\title{
Epidemiology of surgery in a protracted humanitarian setting: a 20-year retrospective study of Nyarugusu Refugee Camp, Kigoma, Western Tanzania
}

\author{
Sarah Rapaport ${ }^{1}$, Hilary Ngude², Amber Lekey ${ }^{3}$, Mohamed Abbas $^{2}$, Peter J. Winch ${ }^{4}$, Kent Stevens ${ }^{1}$ and \\ Zachary Obinna Enumah ${ }^{1,4^{*}}$
}

\begin{abstract}
Background: There are 80 million forcibly displaced persons worldwide, 26.3 million of whom are refugees. Many refugees live in camps and have complex health needs, including a high burden of non-communicable disease. It is estimated that 3 million procedures are needed for refugees worldwide, yet very few studies exist on surgery in refugee camps, particularly protracted refugee settings. This study utilizes a 20-year dataset, the longest dataset of surgery in a refugee setting to be published to date, to assess surgical output in a setting of protracted displacement.
\end{abstract}

Methods: A retrospective review of surgeries performed in Nyarugusu Camp was conducted using paper logbooks containing entries between November 2000 and September 2020 inclusive. Abstracted data were digitized into standard electronic form and included date, patient nationality, sex, age, indication, procedure performed, and anesthesia used. A second reviewer checked 10\% of entries for accuracy. Entries illegible to both reviewers were excluded. Demographics, indication for surgery, procedures performed, and type of anesthesia were standardized for descriptive analysis, which was performed in STATA.

Results: There were 10,799 operations performed over the 20-year period. Tanzanians underwent a quarter of the operations while refugees underwent the remaining $75 \%$. Ninety percent of patients were female and $88 \%$ were 18 years of age or older. Caesarean sections were the most common performed procedure followed by herniorrhaphies, tubal ligations, exploratory laparotomies, hysterectomies, appendectomies, and repairs. The most common indications for laparotomy procedures were ectopic pregnancy, uterine rupture, and acute abdomen. Spinal anesthesia was the most common anesthesia type used. Although there was a consistent increase in procedural volume over the study period, this is largely explained by an increase in overall camp population and an increase in caesarean sections rather than increases in other, specific surgical procedures.

Conclusion: There is significant surgical volume in Nyarugusu Camp, performed by staff physicians and visiting surgeons. Both refugees and the host population utilize these surgical services. This work provides context to the surgical training these settings require, but further study is needed to assess the burden of surgical disease and the extent to which it is met in this setting and others.

\footnotetext{
*Correspondence: zoe@jhmi.edu

1 Global Surgery Initiative, Department of Surgery, Johns Hopkins

Hospital, Baltimore, MD, USA

Full list of author information is available at the end of the article
}

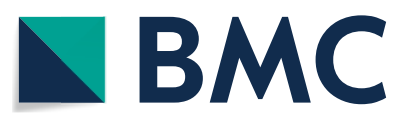

(c) The Author(s) 2021. Open Access This article is licensed under a Creative Commons Attribution 4.0 International License, which permits use, sharing, adaptation, distribution and reproduction in any medium or format, as long as you give appropriate credit to the original author(s) and the source, provide a link to the Creative Commons licence, and indicate if changes were made. The images or other third party material in this article are included in the article's Creative Commons licence, unless indicated otherwise in a credit line to the material. If material is not included in the article's Creative Commons licence and your intended use is not permitted by statutory regulation or exceeds the permitted use, you will need to obtain permission directly from the copyright holder. To view a copy of this licence, visit http://creativecommons.org/licenses/by/4.0/. The Creative Commons Public Domain Dedication waiver (http://creativeco mmons.org/publicdomain/zero/1.0/) applies to the data made available in this article, unless otherwise stated in a credit line to the data. 
Keywords: Global surgery, Refugee camp, Humanitarian setting, Global Health, Tanzania

\section{Introduction}

Worldwide, there are 80 million forcibly displaced persons (FDPs) including 26.3 million refugees, according to the United Nations High Commissioner for Refugees (UNHCR) [1]. 2.6 million refugees live in camps, which are temporary facilities intending to offer short term medical care, nutrition, shelter, and other basic emergency services [2]. Sixteen million are protracted refugees, defined as those who have lived in exile for at least 5 years and are unable to return home, but have not been granted permanent residence in another country [3].

FDPs and refugees have complex health needs, as they face the triple burden of non-communicable disease, infectious disease, and mental health needs [4]. Up to 3 million surgical procedures are needed for displaced persons worldwide according to a 2014 analysis, although this number is likely an underestimate as there were 59.5 million FDPs at the time of analysis, 20 million less than today [5]. Because $86 \%$ of displaced people are hosted in low- and middle-income countries (LMIC), refugees often present to care in settings with limited resources and constrained health systems [1]. Constrained health systems often lack safe, accessible, and affordable surgical care, with the Lancet Commission on Global Surgery reporting that $90 \%$ of the 5 billion people lacking surgical care worldwide reside in a LMIC [6]. Even though $28-32 \%$ of the global burden of disease is surgical in nature, research on surgery in refugee settings lags the demand for knowledge driven by the growing global surgery movement [7]. Despite a large increase in the global surgery literature with PubMed showing 570 cumulative articles published through 2005 and over 4000 through 2015, few studies exist on surgery in refugee settings [8]. Refugee camps have been relatively neglected from this field of literature and are even often included among the exclusion criteria [9].

The availability of data on surgical services in humanitarian settings is sparse, as care provision is often prioritized over research. The previous studies that do exist have focused on active conflict settings where the burden of trauma care is predominant [10-13]. Most that have assessed surgery in chronic humanitarian settings, such as the Mae La Camp on the Thai-Myanmar border, Dadaab Camp in Kenya, or Eastern Democratic Republic of Congo utilize datasets spanning 5 years or less [14-16]. The goal of this study is to describe patterns of surgery over a 20 -year period from a setting of protracted displacement in Western Tanzania. To our knowledge, this is the largest retrospective registry of surgical output from a refugee setting.

\section{Methods}

\section{Study setting and population}

Nyarugusu Camp was created in 1996 for refugees fleeing civil wars in the Democratic Republic of Congo (DRC). It remains in existence today and is classified as a protracted refugee setting. Nyarugusu Camp is located in the Kigoma province in Western Tanzania, which has a long history of hosting refugees. Currently, Tanzania hosts over 286,000 refugees and asylum seekers with $85 \%$ residing in one of three camps: Nyarugusu as the largest, followed by Nduta and Mtendeli [17]. Nyarugusu Camp currently hosts about 133,000 refugees primarily from DRC and more recently Burundi, as political unrest in 2015 caused a dramatic increase in the number of Burundian refugees living in the camp [18]. As of July 2018, the camp population was $51 \%$ female and $55 \%$ of residents were under the age of $17,42 \%$ were adults between the ages of $17-59$, and 3\% were aged 60 and over [19]. Nyarugusu Camp is run by the Tanzania Ministry of Home Affairs and the United Nations High Commissioner for Refugees (UNHCR), with additional operational and implementation support provided by a number of non-governmental (NGOs) and multilateral organizations including Oxfam, the UN World Food Program, UNICEF, and the International Rescue Committee to name a few. Chronic underfunding of this humanitarian health system, measured in April 2021 as operating at a deficit of $\$ 119,063,768$ (only $8 \%$ of need is met) poses a challenge in this setting [20].

The Tanzanian Red Cross Society coordinates camp medical services, which includes supporting one main dispensary hospital, two health centers where patients can be admitted, and multiple health posts that serve both refugees and local Tanzanians. The total catchment population for the health centers and health posts is estimated to be approximately 200,000, and over 20,000 outpatients (refugees and Tanzanians) seek care at the hospital per month [21]. Although local Tanzanian district hospitals charge fees for both refugees and Tanzanians, services provided in the camp are free of cost for both refugees and Tanzanians [22]. If a case cannot be managed within the camp due to its complexity, refugees are referred to facilities outside of the camp according to UNHCR referral guidelines and local operating procedures [23]. 
The operating suite in Nyarugusu Camp consists of two major operating rooms and one minor operating room, and all performed procedures are recorded in paper logbooks that are maintained by camp staff. The major procedure operating room is reserved for procedures involving extensive resection (e.g. entering a body cavity or removing an organ). Surgeries are usually carried out by one of the medical doctors working with a humanitarian organization. In recent years, these are individuals who have completed medical school and an internship year. None have completed a formal residency in general surgery, but most have obtained some surgical training through apprenticeship. In more infrequent circumstances, visiting medical teams may also provide surgical care on repeated humanitarian mission trips (including authors KAS and ZOE). These trips have ranged from 1 to 6 weeks in duration. Within the timeframe of data collection, an earthquake damaged the former single operating room, which catalyzed the construction of a new building that houses the current two major operating rooms and one minor operating room.

\section{Data collection}

A retrospective review of surgeries performed in the major operating room at Nyarugusu Camp was conducted using the paper surgery record logbooks containing entries between November 2000 and September 2020 inclusive. Abstracted data included the day, date, and time of surgery; patient nationality, sex and age; indication for procedure, procedure performed, anesthesia used, post-operative diagnosis, and Apgar score. Unfortunately, outcome data were only descriptive ("good", "fair") and inconsistently recorded, and therefore were not collected for this analysis. While mortality logbooks are maintained in this specific camp, there is no linked database to the operating room logbooks.

\section{Statistical analysis}

Data were digitized from handwritten logbooks into standardized electronic form using Microsoft Excel and a second team member reviewed $10 \%$ of entries for accuracy. Each operation included between one and three procedures, one and three kinds of anesthesia, and some operations could have been performed on the same patient, as data was analyzed in a de-identified fashion for privacy reasons. Any entries that could not be read by either reviewer were marked as illegible. Demographics, procedure performed, indication for procedure, and type of anesthesia were standardized for analysis. Index operations that consisted of more than one procedure for a given patient (e.g., caesarean section plus bilateral tubal ligation or herniorrhaphy plus hydrocelectomy) were each coded to its respective operation as a binary variable. Descriptive analyses were performed for patient nationality, age, sex, procedure type, indication, and anesthesia used. Due to inconsistent reporting of time of day, post-operative diagnosis, and Apgar scores, these values were excluded from analysis. Of note, data were only available for November and December of 2000 and from January to September of 2020. Other years included data for all months of the calendar year. All analyses were performed using STATA statistical software (Version 16. StataCorp; College Station, TX).

\section{Ethics approval}

This study was approved by both the Johns Hopkins Institutional Review Board and the Tanzanian Commission on Science and Technology (COSTECH). Informed consent was waived by the Johns Hopkins Institutional Review Board. All methods were conducted according to relevant guidelines and regulations.

\section{Results \\ Demographics}

A total of 10,799 unique operations were performed over the 20-year study period. After excluding entries for which the year variable was missing, there were a total of 10,780 operations (Table 1). Tanzanians underwent $25 \%$ of major operations $(n=2719)$. Fifty-five percent of refugees who had operations were from the Democratic Republic of Congo (DRC) $(n=5894), 16 \%$ were from Burundi $(n=1707)$ and $2 \%$ were from other nations $(n=158)$, which included Rwanda, Kenya, and those recorded in the logbook as "refugee." An additional 3\% $(n=302)$ were missing the nationality categorization, which are represented in the "missing" category. Ninety percent of the patients were female $(\mathrm{n}=9722)$ and $88 \%$ were 18 years of age or older $(n=9539)$. Individuals aged between 18-29 years were the most represented age category $(\mathrm{n}=6073 ; 56 \%)$ followed by those between $30-44$ $(\mathrm{n}=2670 ; 25 \%)$, pediatric patients between the ages of $0-17(\mathrm{n}=1241 ; 12 \%)$, and patients over $60(\mathrm{n}=224 ; 2 \%)$. An additional 2\% $(n=225)$ were missing the age variable and are represented in the "missing" category.

\section{Demographic changes over time}

The volume of surgery increased over the 20-year study period (Table 2). When stratified into 5-year time periods, there was a steady increase in procedural output with 1609 procedures performed between November 2000-2005; 1812 performed between 2006-2010; 3244 performed between 2011-2015; and 4115 performed between 2016-September 2020 (Table 1; Fig. 1). While the study population composition of refugees (those from DRC, Burundi, and other) versus Tanzanians remained relatively constant over the study period, 
Table 1 Demographics by 5-year time periods

\begin{tabular}{|c|c|c|c|c|c|}
\hline & Overall 2000-2020 & $2000-2005$ & $2006-2010$ & 2011-2015 & $2016-2020$ \\
\hline $\mathrm{N}$ & $10,780^{\mathrm{a}}$ & 1609 & 1812 & 3244 & 4115 \\
\hline \multicolumn{6}{|l|}{ Age (in years) } \\
\hline Average (SD) & $26.3(10.6)$ & $28.0(13.6)$ & $26.0(10.6)$ & $26.0(10.3)$ & $26.2(9.5)$ \\
\hline Under 18 & $1241(11.5 \%)$ & $245(15.2 \%)$ & $287(15.8 \%)$ & $424(13.1 \%)$ & $285(6.9 \%)$ \\
\hline Age 18 to 29 & $6073(56.3 \%)$ & $716(44.5 \%)$ & 919 (50.7\%) & $1779(54.8 \%)$ & $2659(64.6 \%)$ \\
\hline Age 30 to 44 & $2670(24.8 \%)$ & $382(23.7 \%)$ & 487 (26.9\%) & $859(26.5 \%)$ & $942(22.9 \%)$ \\
\hline Age 45 to 60 & $347(3.2 \%)$ & $84(5.2 \%)$ & $65(3.6 \%)$ & $111(3.4 \%)$ & $87(2.1 \%)$ \\
\hline Age $60+$ & $224(2.1 \%)$ & $75(4.7 \%)$ & $29(1.6 \%)$ & $46(1.4 \%)$ & $74(1.8 \%)$ \\
\hline Missing & $225(2.1 \%)$ & $107(6.7 \%)$ & $25(1.4 \%)$ & $25(0.8 \%)$ & $68(1.7 \%)$ \\
\hline \multicolumn{6}{|l|}{ Sex } \\
\hline Male & $992(9.2 \%)$ & $291(18.1 \%)$ & $173(9.5 \%)$ & $257(7.9 \%)$ & $271(6.6 \%)$ \\
\hline Female & $9722(90.2 \%)$ & $1302(80.9 \%)$ & $1624(89.6 \%)$ & $2979(91.8 \%)$ & $3817(92.8 \%)$ \\
\hline Missing & $66(0.6 \%)$ & $16(1.0 \%)$ & $15(0.8 \%)$ & $8(0.2 \%)$ & $27(0.7 \%)$ \\
\hline \multicolumn{6}{|l|}{ Nationality } \\
\hline DRC & $5894(54.7 \%)$ & $1228(76.3 \%)$ & $1337(73.8 \%)$ & $1868(57.6 \%)$ & $1461(35.5 \%)$ \\
\hline Burundi & 1707 (15.8\%) & $2(0.1 \%)$ & $0(0.0 \%)$ & $267(8.2 \%)$ & $1438(34.9 \%)$ \\
\hline Tanzanian & $2719(25.2 \%)$ & $286(17.8 \%)$ & $462(25.5 \%)$ & $981(30.2 \%)$ & $990(24.1 \%)$ \\
\hline Other & $158(1.5 \%)$ & $7(0.4 \%)$ & $1(0.1 \%)$ & $84(2.6 \%)$ & $66(1.6 \%)$ \\
\hline Missing & 302 (2.8\%) & $86(5.3 \%)$ & 12 (0.7\%) & 44 (1.4\%) & 160 (3.9\%) \\
\hline
\end{tabular}

${ }^{\text {a }}$ Records that were missing a year variable were excluded $(n=19)$

Table 2 Operations by year and nationality

\begin{tabular}{llllll}
\hline & Total & DRC & Burundi & Tanzanian & Other \\
\hline N & $10.492^{\mathrm{a}}$ & 5898 & 1714 & 2722 & 158 \\
Year & & & & & \\
2000 & $6(0.1 \%)$ & $0(0.0 \%)$ & $0(0.0 \%)$ & $0(0.0 \%)$ & $6(3.8 \%)$ \\
2001 & $202(1.9 \%)$ & $166(2.8 \%)$ & $1(0.1 \%)$ & $35(1.3 \%)$ & $0(0.0 \%)$ \\
2002 & $320(3.0 \%)$ & $266(4.5 \%)$ & $1(0.1 \%)$ & $53(1.9 \%)$ & $0(0.0 \%)$ \\
2003 & $257(2.4 \%)$ & $206(3.5 \%)$ & $0(0.0 \%)$ & $51(1.9 \%)$ & $0(0.0 \%)$ \\
2004 & $356(3.4 \%)$ & $270(4.6 \%)$ & $0(0.0 \%)$ & $85(3.1 \%)$ & $1(0.6 \%)$ \\
2005 & $382(3.6 \%)$ & $320(5.4 \%)$ & $0(0.0 \%)$ & $62(2.3 \%)$ & $0(0.0 \%)$ \\
2006 & $344(3.3 \%)$ & $276(4.7 \%)$ & $0(0.0 \%)$ & $68(2.5 \%)$ & $0(0.0 \%)$ \\
2007 & $296(2.8 \%)$ & $235(4.0 \%)$ & $0(0.0 \%)$ & $61(2.2 \%)$ & $0(0.0 \%)$ \\
2008 & $311(3.0 \%)$ & $230(3.9 \%)$ & $0(0.0 \%)$ & $81(3.0 \%)$ & $0(0.0 \%)$ \\
2009 & $377(3.6 \%)$ & $258(4.4 \%)$ & $0(0.0 \%)$ & $119(4.4 \%)$ & $0(0.0 \%)$ \\
2010 & $472(4.5 \%)$ & $338(5.7 \%)$ & $0(0.0 \%)$ & $133(4.9 \%)$ & $1(0.6 \%)$ \\
2011 & $447(4.3 \%)$ & $345(5.8 \%)$ & $1(0.1 \%)$ & $101(3.7 \%)$ & $0(0.0 \%)$ \\
2012 & $567(5.4 \%)$ & $379(6.4 \%)$ & $7(0.4 \%)$ & $175(6.4 \%)$ & $6(3.8 \%)$ \\
2013 & $637(6.1 \%)$ & $405(6.9 \%)$ & $11(0.6 \%)$ & $220(8.1 \%)$ & $1(0.6 \%)$ \\
2014 & $724(6.9 \%)$ & $414(7.0 \%)$ & $7(0.4 \%)$ & $267(9.8 \%)$ & $36(22.8 \%)$ \\
2015 & $825(7.9 \%)$ & $325(5.5 \%)$ & $241(14.1 \%)$ & $218(8.0 \%)$ & $41(25.9 \%)$ \\
2016 & $792(7.5 \%)$ & $290(4.9 \%)$ & $296(17.3 \%)$ & $170(6.2 \%)$ & $36(22.8 \%)$ \\
2017 & $805(7.7 \%)$ & $293(5.0 \%)$ & $260(15.2 \%)$ & $224(8.2 \%)$ & $28(17.7 \%)$ \\
2018 & $821(7.8 \%)$ & $282(4.8 \%)$ & $350(20.4 \%)$ & $188(6.9 \%)$ & $1(0.6 \%)$ \\
2019 & $965(9.2 \%)$ & $388(6.6 \%)$ & $317(18.5 \%)$ & $259(9.5 \%)$ & $1(0.6 \%)$ \\
2020 & $572(5.5 \%)$ & $208(3.5 \%)$ & $215(12.5 \%)$ & $149(5.5 \%)$ & $0(0.0 \%)$ \\
Miss- & $14(0.1 \%)$ & $4(0.1 \%)$ & $7(0.4 \%)$ & $3(0.1 \%)$ & $0(0.0 \%)$ \\
ing & & & & & \\
\hline
\end{tabular}

${ }^{a}$ Total 10,492 records given 307 records (2.8\%) with missing data on nationality

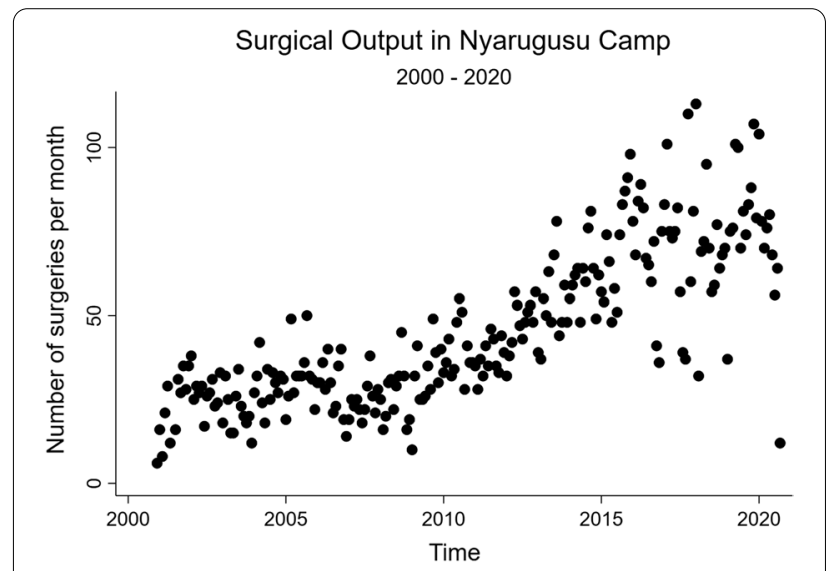

Fig. 1 Total number of operations by month over time. * Of note, the year 2000 includes November and December only and the year 2020 includes January to September only

there was a drastic increase in the proportion of refugees from Burundi between 2016-2020 and a consequential decrease in the proportion of refugees from DRC over that same period (Table 1; Fig. 2).

\section{Procedures performed}

Caesarean sections were the most common procedure performed over the study period $(n=8461 ; 79 \%)$ (Table 3). Caesarean sections were most often performed 


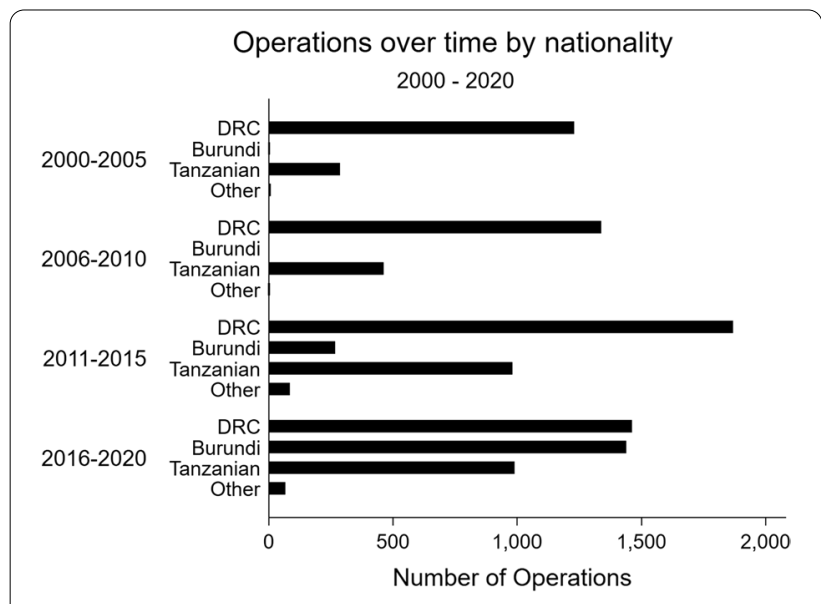

Fig. 2 Operations by nationality over time

on individuals from the DRC, followed by Tanzania, Burundi, and other nations (Fig. 3). Other common procedures include herniorrhaphies $(\mathrm{n}=741,7 \%)$, tubal ligations $(\mathrm{n}=735 ; 7 \%)$, exploratory laparotomies $(\mathrm{n}=555$; $5 \%)$, hysterectomies $(\mathrm{n}=220 ; 2 \%)$, appendectomies $(\mathrm{n}=142 ; 1 \%)$, and repairs $(\mathrm{n}=128 ; 1 \%)$ (Table 3; Fig. 4$)$. Repair is a heterogeneous procedure code, and its indications span various organs and tissues in the body; example indications for a repair include perineal tear, cleft lip, abdominal perforation, cervical tear, and post-partum hemorrhage. Of note, procedures recorded as "repair" for a hernia were recorded as herniorrhaphy rather than repair. Although there was an increase in procedural volume over the study period, this is largely explained by an increase in total camp population and an increase in

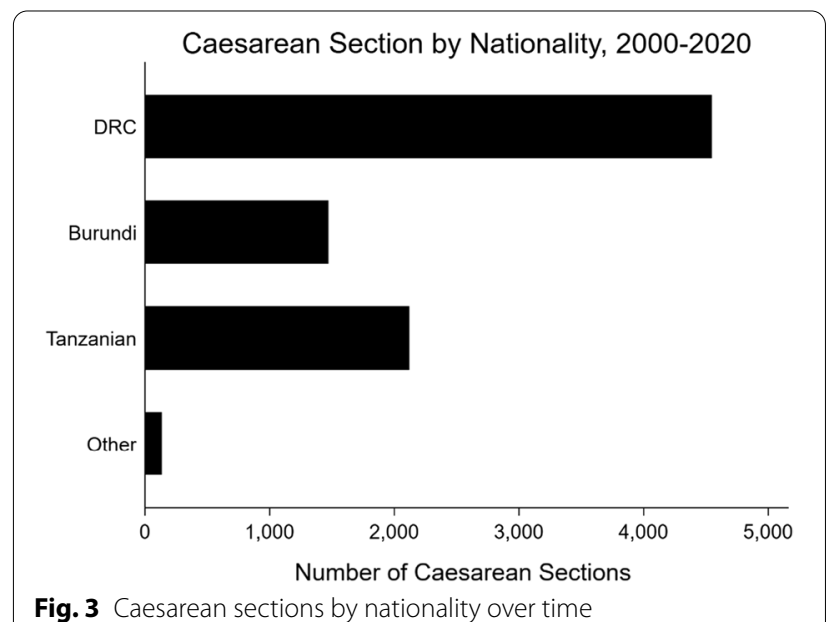

caesarean sections rather than increases in the performance of other kinds of surgical procedures (Fig. 5).

\section{Indications for exploratory laparotomy}

The most common indications for exploratory laparotomy were ectopic pregnancy $(\mathrm{n}=84 ; 15 \%)$, uterine rupture $(\mathrm{n}=76 ; 14 \%)$, acute abdomen $(\mathrm{n}=74 ; 13 \%)$, ovarian cyst removal $(\mathrm{n}=44 ; 8 \%)$, and intestinal obstruction $(\mathrm{n}=27 ; 5 \%)$ (Table 4). Thirty-one entries (6\%) that had the procedure of exploratory laparotomy were missing an indication.

\section{Anesthesia use}

Spinal anesthesia was the most common anesthesia type used $(n=6963 ; 65 \%)$ followed by general $(n=3839$;

Table 3 Common operations over time

\begin{tabular}{|c|c|c|c|c|c|}
\hline & Total & $2000-2005$ & $2006-2010$ & 2011-2015 & $2016-2020$ \\
\hline N & 10,780 & 1609 & 1812 & 3244 & 4115 \\
\hline Caesarean section & $8461(78.5 \%)$ & $1041(64.7 \%)$ & $1463(80.7 \%)$ & $2571(79.3 \%)$ & $3386(82.3 \%)$ \\
\hline Herniorrhaphy & $741(6.9 \%)$ & $209(13.0 \%)$ & $124(6.8 \%)$ & $184(5.7 \%)$ & $224(5.4 \%)$ \\
\hline Bilateral tubal ligation & $735(6.8 \%)$ & $106(6.6 \%)$ & $186(10.3 \%)$ & $273(8.4 \%)$ & $170(4.1 \%)$ \\
\hline Exploratory laparotomy & $555(5.1 \%)$ & $131(8.1 \%)$ & $85(4.7 \%)$ & $182(5.6 \%)$ & $157(3.8 \%)$ \\
\hline Hysterectomy & $220(2.0 \%)$ & $38(2.4 \%)$ & $32(1.8 \%)$ & $73(2.3 \%)$ & $77(1.9 \%)$ \\
\hline Appendectomy & $142(1.3 \%)$ & $18(1.1 \%)$ & $55(3.0 \%)$ & $43(1.3 \%)$ & $26(0.6 \%)$ \\
\hline Repair & $129(1.2 \%)$ & $3(0.2 \%)$ & $3(0.2 \%)$ & $47(1.4 \%)$ & $76(1.8 \%)$ \\
\hline Hydrocelectomy & $129(1.2 \%)$ & $50(3.1 \%)$ & $22(1.2 \%)$ & $23(0.7 \%)$ & $34(0.8 \%)$ \\
\hline Orchidectomy & $40(0.4 \%)$ & $2(0.1 \%)$ & $2(0.1 \%)$ & $22(0.7 \%)$ & $14(0.3 \%)$ \\
\hline Cystectomy & $37(0.3 \%)$ & $7(0.4 \%)$ & $8(0.4 \%)$ & $11(0.3 \%)$ & $11(0.3 \%)$ \\
\hline Hemorrhoidectomy & $22(0.2 \%)$ & $7(0.4 \%)$ & $1(0.1 \%)$ & $5(0.2 \%)$ & $9(0.2 \%)$ \\
\hline Colporrhaphy & $21(0.2 \%)$ & $17(1.1 \%)$ & $0(0.0 \%)$ & $1(0.0 \%)$ & $3(0.1 \%)$ \\
\hline Missing & $90(0.8 \%)$ & $28(1.7 \%)$ & $6(0.3 \%)$ & $19(0.6 \%)$ & 37 (0.9\%) \\
\hline
\end{tabular}




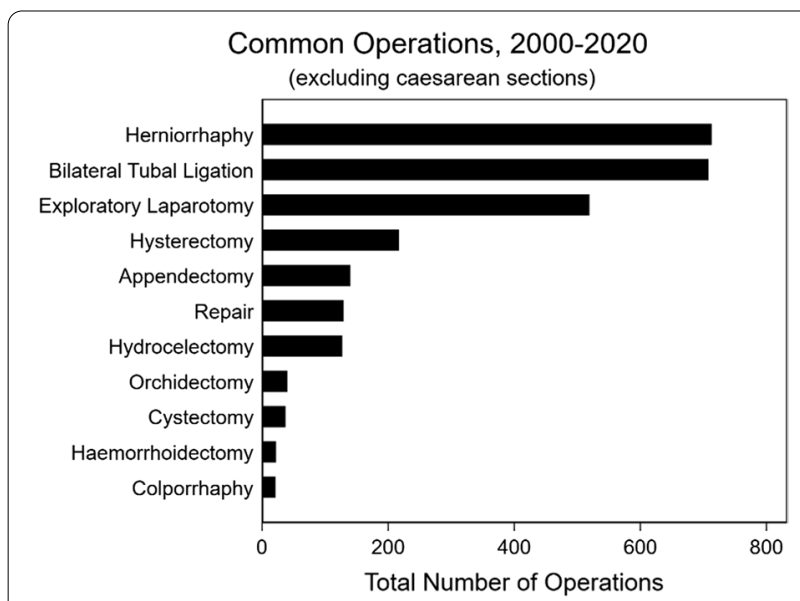

Fig. 4 Common non-caesarean section surgeries

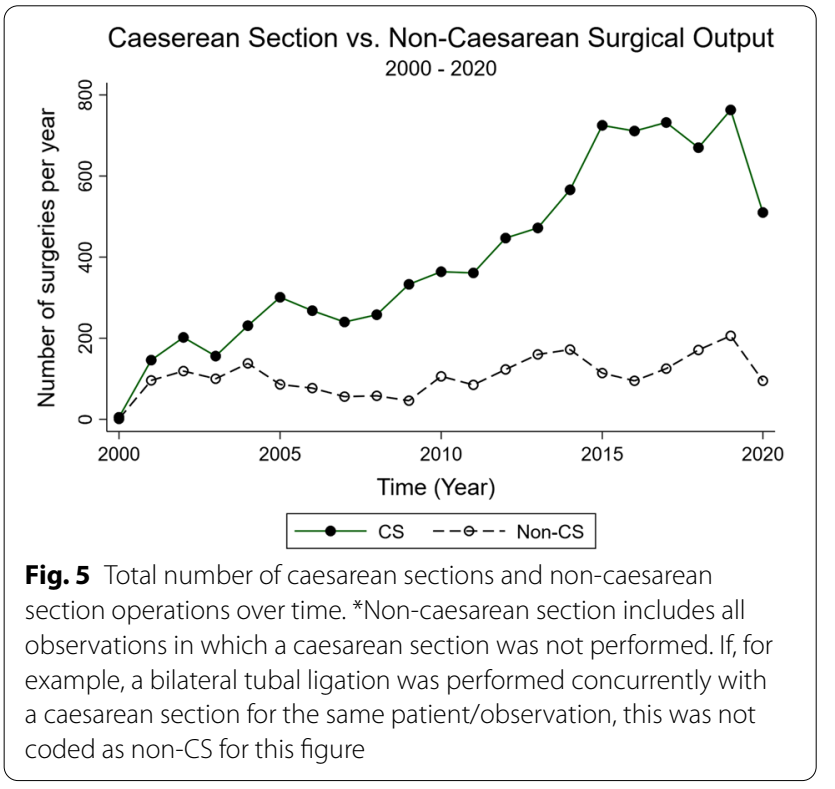

$36 \%)$, local $(n=95 ; 1 \%)$ and other $(n=61 ; 1 \%)$, which includes ketamine, atropine, and valium (Table 5). There were 229 entries (2\%) that were missing an anesthesia categorization. There was considerable variation in the relative proportion of each anesthesia type between the 5 -year time periods.

\section{Discussion}

We sought to explore patterns of surgical output in a protracted refugee setting in Western Tanzania. To our knowledge, this 20-year dataset is the largest analysis of surgical output in a humanitarian setting to be published to date. Our research not only illuminates the patterns of surgery in a protracted humanitarian setting, but also provides valuable quantitative data that can inform policy making, evidence-based program implementation, humanitarian surgical training, and global surgery capacity building efforts.

\section{Demographics}

Demographic analysis revealed that an overwhelming majority of patients were female. Despite $51 \%$ of the camp population being female, this is likely because three of the top five most common operations were caesarean sections, tubal ligations, and hysterectomies. Additionally, there was a notable lack of pediatric surgery in the dataset, with patients under 18 representing only $11.5 \%$ of total operations despite this age group representing $55 \%$ of the camp population. Besides pediatric trauma, which would be represented in the laparotomy category and emergent surgery such as an appendectomy for appendicitis, other pediatric operations may be for congenital abnormalities and require a higher level of operative skill and specialization. These surgeries are not appropriate for management at this dispensary level hospital and are often referred to regional hospitals outside the camp and not recorded in the procedural logbooks. Approximately $25 \%$ of all surgeries performed in the camp were for Tanzanian patients, reflecting a large contribution of this camp-based hospital to treating the host population. While the percentage of Tanzanian patients remained relatively constant over the time period, between 2015 and 2020 there was a proportional decrease in patients from the DRC with a proportional

Table 4 Common indications for exploratory laparotomy over time

\begin{tabular}{|c|c|c|c|c|c|}
\hline & Total 2000-2020 & 2000-2005 & 2006-2010 & 2011-2015 & 2016-2020 \\
\hline N & 555 & 131 & 85 & 182 & 157 \\
\hline Ectopic pregnancy & $84(15.1 \%)$ & 31 (23.7\%) & $8(9.4 \%)$ & $23(12.6 \%)$ & $22(14.0 \%)$ \\
\hline Uterine rupture & $76(13.7 \%)$ & $9(6.9 \%)$ & $7(8.2 \%)$ & $20(11.0 \%)$ & $40(25.5 \%)$ \\
\hline Acute abdomen & $74(13.3 \%)$ & $9(6.9 \%)$ & $20(23.5 \%)$ & $34(18.7 \%)$ & $11(7.0 \%)$ \\
\hline Ovarian cyst & $44(7.9 \%)$ & $11(8.4 \%)$ & $6(7.1 \%)$ & $15(8.2 \%)$ & $12(7.6 \%)$ \\
\hline Intestinal obstruction & $27(4.9 \%)$ & $8(6.1 \%)$ & $10(11.8 \%)$ & $8(4.4 \%)$ & $1(0.6 \%)$ \\
\hline Missing & $31(5.6 \%)$ & $11(8.4 \%)$ & $4(4.7 \%)$ & $7(3.8 \%)$ & $9(5.7 \%)$ \\
\hline
\end{tabular}


Table 5 Anesthesia over time

\begin{tabular}{llllll}
\hline & Total & $\mathbf{2 0 0 0 - 2 0 0 5}$ & $\mathbf{2 0 0 6 - 2 0 1 0}$ & $\mathbf{2 0 1 1 - 2 0 1 5}$ & $\mathbf{2 0 1 6 - 2 0 2 0}$ \\
\hline N & 10,780 & 1609 & 1812 & 3244 & 4115 \\
Spinal anesthesia & $6963(64.6 \%)$ & $788(49.0 \%)$ & $1512(83.4 \%)$ & $1751(54.0 \%)$ & $2912(70.8 \%)$ \\
General anesthesia & $3839(35.6 \%)$ & $676(42.0 \%)$ & $427(23.6 \%)$ & $1545(47.6 \%)$ & $1191(28.9 \%)$ \\
Local anesthesia & $95(0.9 \%)$ & $62(3.9 \%)$ & $3(0.2 \%)$ & $3(0.1 \%)$ & $27(0.7 \%)$ \\
Other anesthesia & $61(0.6 \%)$ & $44(2.7 \%)$ & $3(0.2 \%)$ & $7(0.2 \%)$ & $7(0.2 \%)$ \\
Missing & $229(2.1 \%)$ & $102(6.3 \%)$ & $21(1.2 \%)$ & $21(0.6 \%)$ & $85(2.1 \%)$ \\
\hline
\end{tabular}

increase in patients from Burundi. This largely reflects the shifting overall nationality demographics in the camp as individuals from Burundi arrived as a massive influx of refugees beginning in 2015. Increases in earlier years is likely the result of slow population increases in the camp as a whole.

\section{Characterizing chronic refugee surgery}

Our research highlights that the landscape of surgery in this chronic refugee setting is more related to standard obstetric and general surgical needs rather than acute conflict related trauma care. This is consistent with findings from previous studies in humanitarian settings including those from Thailand, Kenya, and Eastern Democratic Republic of Congo, which found that this kind of disease burden significantly contributes to morbidity but that surgical intervention is cost effective and feasible [14-16]. Research in 1979-1980 from a chronic refugee setting of Cambodian refugees living in Khao I-Dang in Thailand estimated that non-war-related surgery outnumbered war related surgery three to one, emphasizing the need for non-war-related surgical care in these settings $[24,25]$. Our study supports the findings of the previously mentioned ones with a high volume of obstetrical and general surgery procedures.

Our data also mirrors the literature on unmet surgical need in rural sub-Saharan Africa, where Grimes et al. notes caesarean sections and herniorrhaphies as the most common operations [26]. Grimes et al. also notes a lack of laparotomies, which is dissimilar to our finding of laparotomy as one of the most common procedures performed. Despite the lack of emergent, urgent, and elective procedure classification in our dataset, the indications of ectopic pregnancy, uterine rupture, acute abdomen, and intestinal obstruction in the exploratory laparotomy category represent a large amount of the urgent and emergent procedures. Our findings join the aforementioned studies in the notion that chronic refugee surgery differs from emergent refugee surgery, which is defined as care occurring immediately after a precipitating event [24]. Emergent refugee surgery is often trauma based and more closely related to conflict/war setting surgery, while chronic refugee surgery, defined by the literature and supported by our findings, is more related to the basic general surgical need found in underserved or rural settings. The lack of research on chronic refugee surgery is apparent and also documented by Kushner et al. and Broer et al. [24, 27]. While our research adds to the body of literature on surgery in the refugee camp context, our study does not include outcome data, which is generally lacking and needed in the humanitarian surgery space [28]. There is a great need to study surgery in chronic refugee populations worldwide to enable quality assurance, evidence based policy creation, and effective program implementation to better meet demonstrated need. Future studies should also include outcome data to better quantify the effectiveness of these efforts.

\section{Infrastructure limitations}

Anesthesia availability, supported by the predominant use of spinal anesthesia, arose as a major limitation to the nature of procedures performed in this setting. Although challenging to ascertain how exactly this limitation affects procedural capacity, as caesarean sections utilizing spinal anesthesia are the primary procedure in this setting, this trend could show that anesthesia may influence which procedures can be performed in the camp hospital at which times, according to drug availability. An example of this may be the absence of thyroid surgery. This has implications for workforce training, as a provider must be adept at using a breadth of anesthesia options in a variety of conditions, including conditions and patients that may not be best suited to a particular anesthesia type or using anesthesia types different from what might be considered the standard approach in another context. Previous literature regarding anesthesia use in refugee camps is mixed. Data from Red Cross hospitals in Thailand, Lebanon, Pakistan, and Indonesia note that despite a strong preference for spinal and local anesthesia, general is the most commonly used anesthetic [29]. Research from an acute phase camp in Palestine notes that anesthesia was used based on availability and that once supplies diminished, more patients were required to use local or no anesthesia even when not 
ideal [30]. Our findings are consistent with the heterogeneity of anesthesia use. Although spinal is overall the most common anesthesia in our dataset, the frequency fluctuates between 5 -year time periods suggesting anesthesia choice could be dependent on availability. The heterogeneity of this finding and its implications for limiting surgical capacity warrant further study in this setting and others.

The availability of trained surgeons is another limiting factor in humanitarian settings. Nyarugusu Camp has no formally trained general surgeons and surgical care is provided by either a visiting surgical team or Tanzanian general practitioners who have obtained some level of surgical skill. This ad hoc task shifting allows for some level of surgical care in this dispensary level hospital and aids both patients, for they are able to seek timely care at no charge, and Tanzanians, as referral hospitals can be spared the burden of care appropriately treated at dispensary level centers [31]. This care mirrors that provided in a district hospital. The human skill available likely biases the choice of procedures performed, potentially accounting for the majority of operations being caesarean sections. Task shifting in LMICs has been explored elsewhere in the literature. Previous research in Tanzania showed similar outcomes for procedures performed by surgeons and non-physician clinicians [32]. Previous research on task shifting in humanitarian settings has shown no difference in peri-operative mortality, which has prompted calls for the associate clinicians common among the global surgery workforce to be included in plans to build global surgery capacity, despite the recognition that more outcome data are needed [13, 33]. Our findings reflect those of the previous literature in that significant surgical volume can be supported by trained local clinical associates and medical doctors (not specialty trained surgeons) in conjunction with appropriate apprenticeship and mentoring. This explains how this camp, which has no formally trained surgeons, is able to perform a significant amount of surgery, ultimately providing care to a refugee and host population in need and preventing unnecessary referral care from straining national health systems. This has important implications for global surgery workforce training models, especially in humanitarian settings.

\section{Refugee surgery in the context of global surgery}

Both our study and others show that humanitarian surgery services are utilized by host populations, particularly during times of health system stress, which reveals that these programs do not exist in a vacuum but rather contribute to larger national health systems [34]. Understudying refugee settings from the global surgery literature not only illuminates a false landscape of surgical needs and capacities worldwide, but also bypasses the valuable opportunity to improve humanitarian and host population surgical systems together.

\section{Limitations}

Our study is not without limitations. Regarding the dataset itself, the logbooks are maintained by camp medical and administrative staff. Many of them are short term workers and there is heterogeneity and subjectivity in the recorded data. The lack of a standardized recording system, including regulation on how close to the time of a procedure an entry is made, introduces the potential limitation of accuracy of recorded data as it could lead to recall bias. Additionally, inconsistencies in the recorded variables, such as few entries containing post-operative diagnoses or Apgar scores, limited the variables that could be analyzed. This study assessed surgical output of the camp, which does not capture patients with surgical conditions treated at referral hospitals or those with surgical conditions either unaware of their surgical need or choosing not to seek treatment at the camp-based hospitals. As such, a household survey is needed to obtain population level data on the burden of surgical disease in the camp [35]. This has recently been employed in another refugee setting, but none have been conducted in sub-Saharan Africa [36]. Our group is currently conducting a household survey in Nyarugusu Camp. Finally, further delineating the landscape of surgical referral would also allow for a more complete picture of the burden and capacity of surgical disease in this refugee population.

\section{Conclusion}

To our knowledge, this is the longest retrospective study of surgical output in a protracted refugee setting to date. Our findings reveal there is significant surgical volume in this dispensary hospital and a quarter of the patients utilizing these services are local Tanzanians. The most common operations are caesarean sections, herniorrhaphies, tubal ligations, and laparotomies and the most common indications for laparotomies are ectopic pregnancy, uterine rupture, and acute abdomen. The findings of this study can aid administrators in preparing and training the humanitarian workforce. Although this study contributes to the nascent body of literature on surgery in chronic refugee settings, there is a great need for further research related to operative and peri-operative outcomes, the unmet burden of surgical disease, and referral care relating to follow up and procedures deemed too specialized to be performed in the camp dispensary hospital. The growing number of refugees worldwide necessitates the inclusion of this population in global surgery advocacy and capacity building efforts. Further work in this setting and others is critical to formulating data 
driven policy and program implementation to benefit both the refugee and host populations that utilize campbased services.

\section{Acknowledgements}

We would like to acknowledge Tanzanian Red Cross Society and field staff for the opportunity to pursue this research.

\section{Authors' contributions}

Conceptualization: ZOE, SR. Data curation: SR, ZOE, AL. Formal analysis: ZOE. Funding acquisition: ZOE. Project administration/resources: ZOE, PJW. Supervision: PW, KAS, ZOE. Original draft: SR, ZOE. Review and editing: SR, AL, HN, MA, PJW, KAS, ZOE. All authors read and approved the final manuscript.

\section{Funding}

Project supported by American Society of Tropical Medicine and Hygiene Benjamin Keane Fellowship (ZOE), Ruth L. Kirschstein National Research Service Award (NRSA) T32 Appointment (Award: 2T32AR67708-6, Pl: Clemens, T.) (ZOE), Association for Academic Surgery Global Surgery Research Fellowship (ZOE), and Johns Hopkins School of Medicine Dean's Summer Research Funding (SR, ZOE).

\section{Availability of data and materials}

Data used and analyzed in the current study are not publicly available due to privacy and personally identifiable health information. De-identified, aggregate data is available from corresponding author upon request.

\section{Declarations}

\section{Ethics approval and consent to participate}

The study was approved by the Johns Hopkins Institutional Review Board and Tanzanian Commission on Technology and Science.

\section{Consent for publication}

Not applicable.

\section{Informed consent}

Waived by the Johns Hopkins IRB.

\section{Competing interests}

The authors declare no competing interests.

\section{Author details}

${ }^{1}$ Global Surgery Initiative, Department of Surgery, Johns Hopkins Hospital, Baltimore, MD, USA. ${ }^{2}$ Tanzania Red Cross Society, Dar es Salaam, Tanzania. ${ }^{3}$ Boston University School of Medicine, Boston, MA, USA. ${ }^{4}$ Department of International Health, Johns Hopkins School of Public Health, Baltimore, MD, USA.

Received: 12 May 2021 Accepted: 27 September 2021

Published online: 29 October 2021

\section{References}

1. Refugees UNHC for. UNHCR — Refugee statistics. UNHCR. https://www. unhcr.org/refugee-statistics/. Accessed 30 Apr 2021.

2. Turner $\mathrm{S}$. What is a refugee camp? Explorations of the limits and effects of the camp. J Refug Stud. 2016;29:139-48.

3. Chimni BS. From resettlement to involuntary repatriation: towards a critical history of durable solutions to refugee problems. Refug Surv Q. 2004;23:55-73.

4. Abbas M, Aloudat T, Bartolomei J, Carballo M, Durieux-Paillard S, Gabus $L$, et al. Migrant and refugee populations: a public health and policy perspective on a continuing global crisis. Antimicrob Resist Infect Control. 2018;7:113. https://doi.org/10.1186/s13756-018-0403-4.

5. Zha Y, Stewart B, Lee E, Remick KN, Rothstein DH, Groen RS, et al. Global estimation of surgical procedures needed for forcibly displaced persons. World J Surg. 2016;40:2628-34.
6. Meara JG, Leather AJM, Hagander L, Alkire BC, Alonso N, Ameh EA, et al. Global surgery 2030: evidence and solutions for achieving health, welfare, and economic development. The Lancet. 2015;386:569-624.

7. Shrime MG, Bickler SW, Alkire BC, Mock C. Global burden of surgical disease: an estimation from the provider perspective. Lancet Glob Health. 2015;3:S8-9.

8. Niyikuri A, Smith ER, Vervoort D, Shrime MG, Brown S, Peters AW, et al. Top 10 resources in global surgery. Glob Health Sci Pract. 2020;8:606-11.

9. Pittalis C, Brugha R, Gajewski J. Surgical referral systems in low- and middle-income countries: a review of the evidence. PLOS ONE. 2019;14:e0223328. https://doi.org/10.1371/journal.pone.0223328.

10. Jain RP, Meteke S, Gaffey MF, Kamali M, Munyuzangabo M, Als D, et al. Delivering trauma and rehabilitation interventions to women and children in conflict settings: a systematic review. BMJ Glob Health. 2020;5 Suppl 1:e001980.

11. Gargavanis AA, Kanistra KA, Diamantopoulos K, Liasis D, Photiou E, Giakoustidis DE, et al. Multi-trauma injuries and level of preparedness in transit refugee camps: a case in Idomeni, Greece. Med Confl Surviv. 2019;35:133-9.

12. Hornez E, Ramiara P, Mocellin N, Bajard X, Legoudeveze S, Charpail C, et al. Surgical management of Syria's war casualties: experience from a French surgical team deployed in the Zaatari refugee camp (Jordan). Eur J Trauma Emerg Surg. 2015;41:143-7.

13. Chu KM, Ford NP, Trelles M. Providing surgical care in Somalia: a model of task shifting. Confl Health. 2011;5:12.

14. Weerasuriya CK, Tan SO, Alexakis LC, Set AK, Rijken MJ, Martyn P, et al. Evaluation of a surgical service in the chronic phase of a refugee camp: an example from the Thai-Myanmar border. Confl Health. 2012;6:95.

15. Wu VK, Poenaru D. Burden of surgically correctable disabilities among children in the Dadaab Refugee Camp. World J Surg. 2013;37:1536-43.

16. Chu K, Havet P, Ford N, Trelles M. Surgical care for the direct and indirect victims of violence in the eastern Democratic Republic of Congo. Confl Health. 2010;4:6.

17. UNHCR Tanzania Fact Sheet: January-March 2020. UNHCR operational data portal (ODP). https://data2.unhcr.org/en/documents/details/76872. Accessed 26 Mar 2021.

18. Tanzania Refugee Population Update (as of 28 February 2021)—United Republic of Tanzania. ReliefWeb. https://reliefweb.int/report/unitedrepublic-tanzania/tanzania-refugee-population-update-28-february2021. Accessed 14 May 2021.

19. North-West Tanzania - Nyarugusu Refugee Camp Profile (31 July 2018)— United Republic of Tanzania. ReliefWeb. https://reliefweb.int/report/ united-republic-tanzania/north-west-tanzania-nyarugusu-refugee-campprofile-31-july-2018. Accessed 22 Mar 2021.

20. United Republic of Tanzania| Global Focus. https://reporting.unhcr.org/ tanzania. Accessed 24 Apr 2021.

21. Refugees UNHC for. Cash-strapped camp hospitals struggle to save lives in Tanzania. UNHCR. https://www.unhcr.org/news/stories/2018/1/5a38d c824/cash-strapped-camp-hospitals-struggle-save-lives-tanzania.html. Accessed 22 Mar 2021.

22. Tanzania Refugee Situation Public Health and Nutrition Strategy 2016-2018-United Republic of Tanzania. ReliefWeb. https://reliefweb. int/report/united-republic-tanzania/tanzania-refugee-situation-publichealth-and-nutrition-strategy-2016. Accessed 22 Mar 2021.

23. United Nations High Commissioner for. UNHCR's Principles and Guidance for Referral Health Care for Refugees and Other Persons of Concern. UNHCR. 2009. https://www.unhcr.org/protection/health/4b4c4fca9/ unhcrs-principles-guidance-referral-health-care-refugees-other-persons. html. Accessed 11 Dec 2020.

24. Kushner AL, Groen RS, Kingham TP. Surgery and refugee populations. Scand J Surg. 2009;98:18-24.

25. US Department of Health and Human Services: Public Health Service: Centers for Disease Control. Emergency refugee health care: a chronicle of experience in the Khmer Assistance Operation 1979-1980. p. 85-8.

26. Grimes CE, Law RSL, Borgstein ES, Mkandawire NC, Lavy CBD. Systematic review of met and unmet need of surgical disease in rural Sub-Saharan Africa. World J Surg. 2012;36:8-23.

27. NiclasBroer $P$, Juran $S$. Surgical needs of refugee populations in the European Union: implications for plastic and reconstructive surgery. World J Plast Surg. 2016;5:325-7. 
28. Chu KM, Trelles M, Ford NP. Quality of care in humanitarian surgery. World J Surg. 2011;35:1169-72.

29 Lenz G, Klöss T, Bauer J, Buschmann JP, Dietrich W, Hering M, et al. Anesthesiologic treatment of 3,665 patients in Red Cross hospitals in Thailand, Lebanon, Pakistan and Indonesia. Anasth Intensivther Notfallmed. 1985;20:261-5.

30. Cutting PA, Agha R. Surgery in a Palestinian refugee camp. Injury. 1992;23:405-9.

31. Jumbam DT, Menon G, Lama TN, Lodge W II, Maongezi S, Kapologwe NA, et al. Surgical referrals in Northern Tanzania: a prospective assessment of rates, preventability, reasons and patterns. BMC Health Serv Res. 2020:20:725.

32. Beard JH, Oresanya LB, Akoko L, Mwanga A, Mkony CA, Dicker RA. Surgical task-shifting in a low-resource setting: outcomes after major surgery performed by nonphysician clinicians in Tanzania. World J Surg. 2014:38:1398-404.
33. Federspiel F, Mukhopadhyay S, Milsom PJ, Scott JW, Riesel JN, Meara JG. Global surgical, obstetric, and anesthetic task shifting: a systematic literature review. Surgery. 2018;164:553-8.

34 Naidoo M, Naidu P, Shrime MG, Chu KM. Humanitarian surgical care delivery: lessons for global surgical systems strengthening. J Public Health Emerg. 2020;4:22. https://doi.org/10.21037/jphe-20-79.

35. Resources. Surgeons Overseas. https://www.surgeonsoverseas.org/resou rces/. Accessed 15 Apr 2021

36 Moustafa MK, Al-Haji S, El-Hechi M, El Moheb M, Chamseddine Z, Kaafarani HMA. The burden of surgical disease and access to care in a vulnerable Syrian refugee population in Lebanon. World J Surg. 2021;45:3019-26.

\section{Publisher's Note}

Springer Nature remains neutral with regard to jurisdictional claims in published maps and institutional affiliations.
Ready to submit your research? Choose BMC and benefit from:

- fast, convenient online submission

- thorough peer review by experienced researchers in your field

- rapid publication on acceptance

- support for research data, including large and complex data types

- gold Open Access which fosters wider collaboration and increased citations

- maximum visibility for your research: over $100 \mathrm{M}$ website views per year

At BMC, research is always in progress.

Learn more biomedcentral.com/submissions 